Supplement of Biogeosciences, 12, 1941-1954, 2015

http://www.biogeosciences.net/12/1941/2015/

doi:10.5194/bg-12-1941-2015-supplement

(C) Author(s) 2015. CC Attribution 3.0 License.

(c) (i)

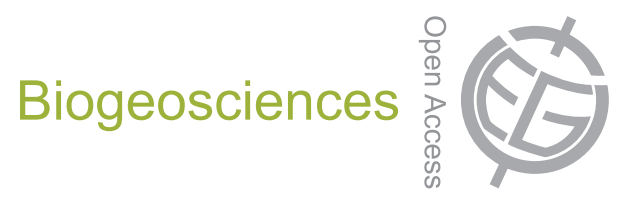

Supplement of

\title{
Riparian and in-stream controls on nutrient concentrations and fluxes in a headwater forested stream
}

\section{S. Bernal et al.}

Correspondence to: S. Bernal (sbernal@ceab.csic.es) 


\section{Supplementary Figures. Bernal et al. BG-2014-324}

a

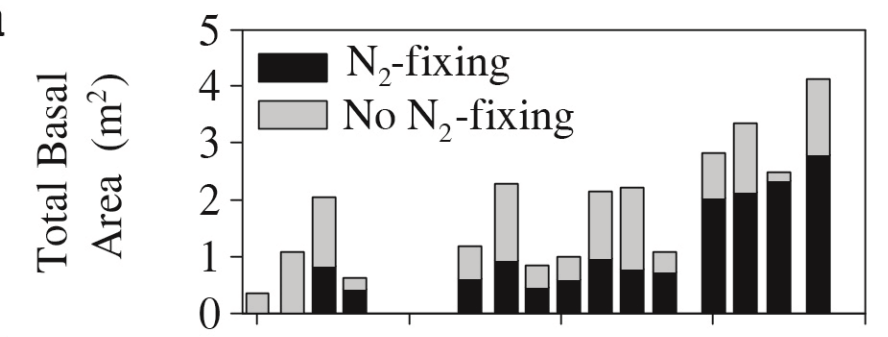

b

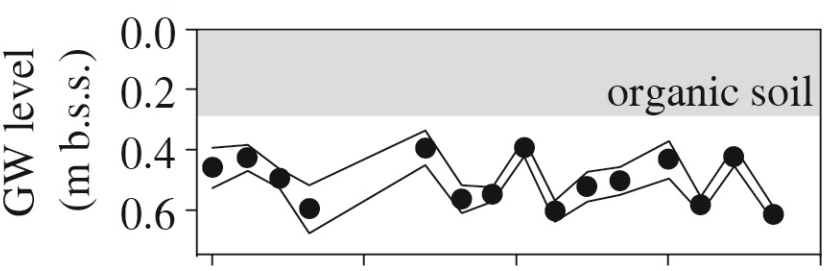

C

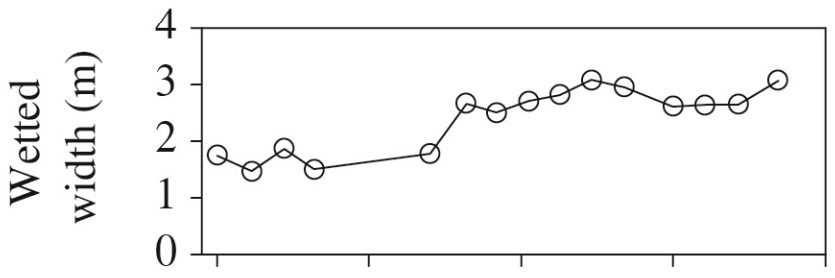

d

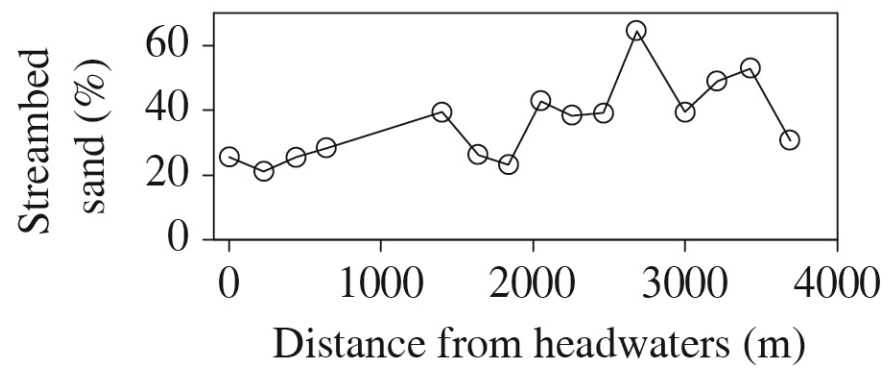

Figure S1. (a) Total basal area of riparian trees, (b) mean riparian groundwater level (in m below the soil surface), (c) stream wetted width, and (d) percentage of sands in streambed for each sampling site along the study reach. Different colors in (a) indicate the basal area of $\mathrm{N}_{2-}$ and no $\mathrm{N}_{2}$-fixing trees. The solid lines in (b) are the $95 \%$ lower and upper values of the riparian groundwater level. 
a

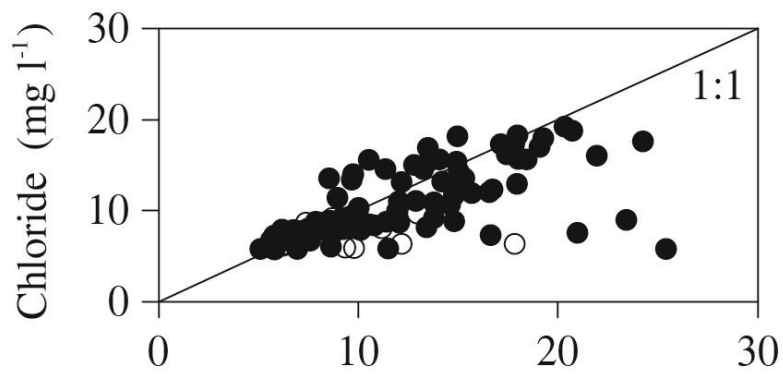

$\mathrm{b}$

Chloride $\left(\mathrm{mg} \mathrm{l}^{-1}\right)$

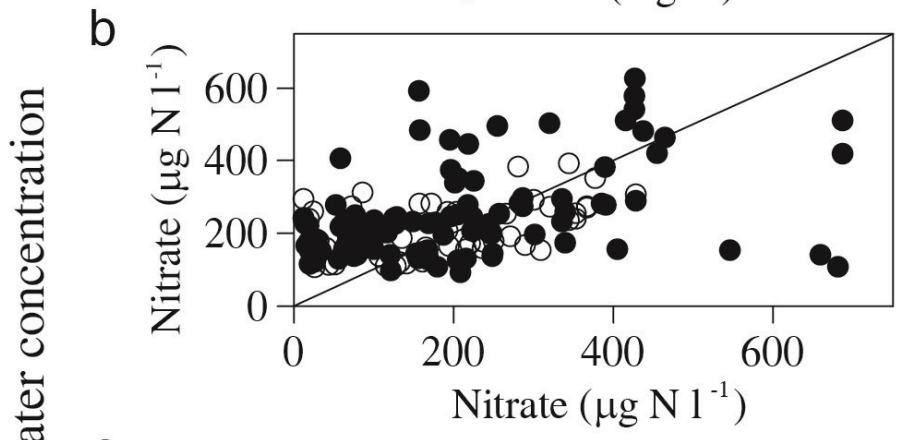

$\mathrm{C} \subsetneq 40$

苂

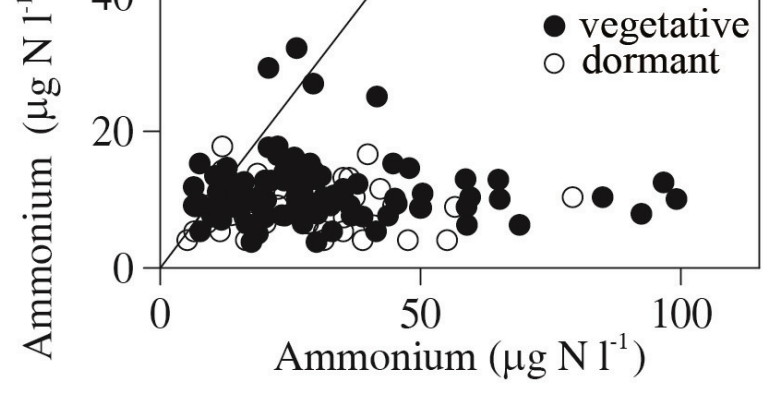

d

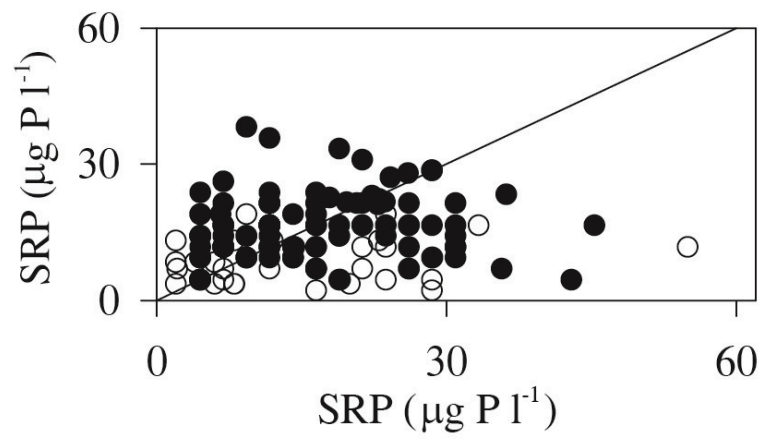

Groundwater concentration

Figure S2. Relationship between riparian groundwater and stream water concentrations for (a) chloride, (b) nitrate, (c) ammonium, and (d) soluble reactive phosphorus at each sampling site and for each sampling date at Font del Regàs. The 1:1 line is indicated in black. 
